\title{
Article \\ Trehalose Effect on The Aggregation of Model Proteins into Amyloid Fibrils
}

\author{
Eleonora Mari ${ }^{1,+}$, Caterina Ricci ${ }^{1,+}\left(\mathbb{D}\right.$, Silvia Pieraccini ${ }^{2}\left(\mathbb{0}\right.$, Francesco Spinozzi $^{1}{ }^{1}$, \\ Paolo Mariani ${ }^{1}$ (D) and Maria Grazia Ortore ${ }^{1, *(D)}$ \\ 1 Department of Life and Environmental Sciences, Polytechnic University of Marche, I-60121 Ancona, Italy; \\ emari1607@gmail.com (E.M.); c.ricci@univpm.it (C.R.); f.spinozzi@univpm.it (F.S.); \\ p.mariani@univpm.it (P.M.) \\ 2 Department of Chemistry “Giacomo Ciamician", University of Bologna, I-40126 Bologna, Italy; \\ silvia.pieraccini@unibo.it \\ * Correspondence: m.g.ortore@univpm.it \\ + These authors contributed equally to this work.
}

Received: 31 March 2020; Accepted: 8 May 2020; Published: 13 May 2020

\begin{abstract}
Protein aggregation into amyloid fibrils is a phenomenon that attracts attention from a wide and composite part of the scientific community. Indeed, the presence of mature fibrils is associated with several neurodegenerative diseases, and in addition these supramolecular aggregates are considered promising self-assembling nanomaterials. In this framework, investigation on the effect of cosolutes on protein propensity to aggregate into fibrils is receiving growing interest, and new insights on this aspect might represent valuable steps towards comprehension of highly complex biological processes. In this work we studied the influence exerted by the osmolyte trehalose on fibrillation of two model proteins, that is, lysozyme and insulin, investigated during concomitant variation of the solution ionic strength due to $\mathrm{NaCl}$. In order to monitor both secondary structures and the overall tridimensional conformations, we have performed UV spectroscopy measurements with Congo Red, Circular Dichroism, and synchrotron Small Angle X-ray Scattering. For both proteins we describe the effect of trehalose in changing the fibrillation pattern and, as main result, we observe that ionic strength in solution is a key factor in determining trehalose efficiency in slowing down or blocking protein fibrillation. Ionic strength reveals to be a competitive element with respect to trehalose, being able to counteract its inhibiting effects toward amyloidogenesis. Reported data highlight the importance of combining studies carried out on cosolutes with valuation of other physiological parameters that may affect the aggregation process. Also, the obtained experimental results allow to hypothesize a plausible mechanism adopted by the osmolyte to preserve protein surface and prevent protein fibrillation.
\end{abstract}

Keywords: small angle X-ray scattering; circular dichroism; spectroscopy; amyloid; trehalose; protein solvation; lysozyme; insulin

\section{Introduction}

A polypeptide chain in the folding process can achieve ordered or disordered structure, depending on the amino acid sequence, and on the physical and chemical features of the environment in which the protein is expressed. In the last decades misfolding of proteins and their aggregation in amyloid fibrils has attracted much attention, in particular from research areas studying neurodegenerative diseases. Amyloid fibrils are in fact commonly recognized as a result of protein misfolding and have been observed both in vitro and in vivo, where their accumulation and deposition into insoluble plaques and intracellular inclusions are the hallmark of several diseases known as amyloidosis. Alzheimer's, Parkinson's, and Huntington's diseases are some of the approximately 
fifty amyloid diseases described to date. Amyloid fibrils, grown from proteins having different size, stability, and charge, share a common structure composed by repetitive sheets in which monomers are joined by hydrogen bonds across $\beta$-strands.

In non-pathological conditions, numerous stabilizing forces contribute to maintaining the correct folding of the protein. On this issue, hydrophobic interactions play a very important role: non-polar amino acids tend to minimize exposure to a polar solvent, such as water, thus locating themselves within the protein structure, while polar and charged amino acids are exposed to the surface of the protein, establishing close interactions with the solvent [1]. In stressful situations, such as extreme variations in temperature and $\mathrm{pH}$, increased ionic strength or mechanical agitation, every protein can lose its native conformation, experiencing the possibility of rearranging into a different conformation or aggregating with other proteins in solution [2-5]. For example, in native conditions a protein has a limited degree of movement and flexibility that can be remarkably increased by increasing the temperature up to the conformation in which the protein exposes on its surface non-polar amino acids. Hence, the protein is allowed to establish protein-protein rather than protein-solvent interactions, with consequent modifications in aggregation and precipitation [6]. Also the presence of salts can mediate protein pathway of aggregation through ion interactions (Debye-Hückel screening or electroselectivity series), or by influencing water-solute interactions (Hofmeister series) [7]. These effects are then a combination of electrostatic and solute-solvent interactions, although many other exogenous and endogenous factors related to the specific protein and environment give their contribution [8-10].

In response to environmental stress, a variety of small molecules, classified as osmolytes, accumulate in cells. These natural species, including amino acids, sugars, polyols, but also tertiary sulphonium and quaternary ammonium compounds, present different interactions in the cellular context. While stabilizing osmolytes have been observed to be preferentially excluded from the protein surface [11,12], denaturing osmolytes like urea exhibit preferential binding to both native and disordered states of the protein $[13,14]$. However, recent Molecular Dynamics results suggest that the differences between protein shell and bulk compositions, in terms of water and cosolvents/cosolutes concentration, exhibit relevant changes with solvent composition, temperature, and protein nature [15]. These results prompt that the role played by a cosolute can change according to its absolute concentration in the environment, as well as according to temperature and to other chemical physical parameters, and it is exactly what osmolytes can do in vivo [16]. Given the osmolytes ability of maintaining the correct folding of proteins, these compounds have been extensively studied in recent years for their application as therapeutic agents in neurodegenerative diseases [17-19]. In particular, trehalose, among others, is able to preserve protein structural integrity, reduces aggregation of pathologically misfolded proteins, and improves the clearance of the mutant proteins which act as autophagy substrates when aberrant protein deposition occurs [20].

Several advances are made to understand and get detailed insight into the structural basis and mechanism of amyloid fibrils formation, cytotoxicity and therapeutic approaches to combat them [21-28]. In particular, when considering results collected on trehalose in the context of protein fibrillation, attention has to be paid also to the external environment characterized by a defined ionic strength and subjected to a particular redistribution of water molecules in proximity of protein surfaces. In particular, physiological ionic strength, while somewhat variable, averages around $155 \mathrm{mM}$, and for this reason it is important to investigate similar experimental conditions.

In this work, the competitive effect of trehalose and ionic strength has been investigated in relation to fibrillation of two model proteins: hen egg white lysozyme and bovine pancreatic insulin.

Specific protocols have been exploited to ensure the conversion of the proteins from their soluble forms into highly ordered, beta-sheeted, fibrillar aggregates under various conditions. The two proteins have been selected for their availability and for their different chemical characteristics.

Lysozyme, a glycosidase of 129 amino acids, in its native conformation has a globular shape. Its isoelectric point is at about 11.2 , at physiological $\mathrm{pH}$ it is positively charged, and it shows a $\alpha+\beta$ 
conformation, with approximately $35 \%$ of the amino acids involved in $\alpha$-helical structures and $10 \%$ involved in $\beta$-sheet structures, depending on the environment and buffer conditions. The structural stability is achieved, among the different forces involved, by four disulphide bridges $[29,30]$. Lysozyme fibrillation in presence of chaotropic anions of the Hofmeister series changes, and the timing of the lag phase is considerably reduced $[31,32]$ even for relatively low concentrations of salt in solution $(<300 \mathrm{mM})$ [33].

Insulin is a small peptide hormone produced in the $\beta$ cells of the pancreatic islets of Langerhans. It is made up of two peptide chains, composed of 21 amino acids and 30 amino acids each. The two chains are linked by two disulphide bridges, while a third disulphide bridge resides inside a single chain. Insulin native form is mainly constituted by $\alpha$-helical structures, and its isoelectric point is at about 5.4, leading its charge at physiological $\mathrm{pH}$ to be negative. It has been reported that its fibrillation is favored by $\mathrm{NaCl}$ that induces subtle structural changes pushing aside the $\mathrm{N}$ - and $\mathrm{C}$-terminal segment, leading to the exposure of highly hydrophobic inner core [34]. The structural tweaking of insulin allows to recruit monomeric units for initial inter-molecular hydrophobic clumping that in turn leads to rapid association of insulin into amyloid fibrils. The propensity of insulin to fibrillate, can cause, besides pathological, also biomedical and biotechnological complications of high relevance, considering its wide therapeutic use in diabetes treatment and the requirement of functional insulin in each pharmaceutical dose [34].

In the light of renewed studies on trehalose behavior in water [35,36], or of trehalose preferential exclusion from protein hydration shell [37], we report on trehalose effect on amyloid fibrillation of two model proteins explored as a function of ionic strength. For this purpose, we have performed spectrophotometric experiments with Congo Red as specific amyloid dye, Circular Dichroism (CD), and Syncrothron Small Angle X-ray Scattering (SAXS) to monitor the temporal evolution of protein fibrillation, either in the absence or in the presence of $\mathrm{NaCl}$.

\section{Materials and Methods}

\subsection{Sample Preparation}

Lysozyme from lyophilized white eggs was purchased from Sigma Aldrich, and it was used at a concentration of $3 \mathrm{mg} / \mathrm{mL}$ dissolved in glycine buffer $(70 \mathrm{mM})$ at $\mathrm{pH}$ 2.3. Lysozyme solution was maintained at $4{ }^{\circ} \mathrm{C}$ overnight, and fibrillation was induced at $65^{\circ} \mathrm{C}$ with gentle agitation according to literature protocols [33]. Bovine pancreatic insulin, purchased from Sigma Aldrich, was dissolved at a concentration of $3 \mathrm{mg} / \mathrm{mL}$ in $\mathrm{HCl}(25 \mathrm{mM})$ at pH 2.0, and kept at a temperature of $4{ }^{\circ} \mathrm{C}$ for one night. Subsequently, the fibrillation process was induced by bringing the sample to a temperature of $65{ }^{\circ} \mathrm{C}$ without agitating, and according to literature [38-40]. For both proteins, samples with or without trehalose and/or $\mathrm{NaCl}$ at various desidered concentrations were prepared.

\subsection{UV-Visible Spectrophotometry}

UV-Visible spectrophotometry, performed in presence of Congo Red (CR), was used to monitor the kinetics of aggregation of lysozyme and insulin into amyloid fibers, either in the absence or in the presence of trehalose and/or $\mathrm{NaCl}$. Due to its high affinity for $\beta$-sheet conformations of fibrillated proteins [41], CR dye has been used as a diagnostic tool for amyloidogenesis since several decades. Indeed, tissues with amyloid aggregates assume, when stained with CR alkaline solutions, an intense red colour under sunlight. In addition, $C R$ bonding with $\beta$-sheet structures induces a characteristic red-shifting of CR absorption maximum in Uv/Vis spectrum, from $\simeq 490 \mathrm{~nm}$ to $\simeq 540 \mathrm{~nm}$. Although CR specificity in this field has been called into question [42], this approach might be considered still valid if used for semi-quantitative analysis and corroborated by other techniques.

Congo Red solution was prepared by CR dissolution in ethanol $(80 \% w / w)$ and addition of $\mathrm{NaCl}$ up to saturation. The obtained solution was saturated with the dye powder and filtered with Millipore filters of pore size $0.2 \mu \mathrm{m}$ to remove possible aggregates. 
Due to characteristic $\mathrm{pH}$-dependent changes in the $\mathrm{CR}$ absorption spectrum, $\mathrm{pH}$ of lysozyme and insulin buffer solutions was brought at about 11.5 with a $\mathrm{NaOH}$ solution before UV/VIS analysis. Then, cuvettes for spectrophotometric measurements were prepared by adding $50 \mu \mathrm{L}$ of the selected protein sample ( $\mathrm{pH} \simeq 2$ ), with $50 \mu \mathrm{L}$ of the Congo Red solution, and $400 \mu \mathrm{L}$ of the buffer used for each protein at $\mathrm{pH}$ 11.5. The amount of $\mathrm{CR}$ that we used for investigation was selected by performing several spectrophotometric measurements on different samples and comparing the obtained results. In particular, different volumes of Congo Red solutions were tested, that is, $10 \mu \mathrm{L}, 30 \mu \mathrm{L}, 50 \mu \mathrm{L}$, $70 \mu \mathrm{L}, 90 \mu \mathrm{L}$, and we considered $50 \mu \mathrm{L}$ as the most appropriate volume. After having verified the good reproducibility of the experiments, we carried out a semi-quantitative analysis finally providing the fraction of $\beta$ structures formed in solution. Indeed, the ratio between absorption intensity at $\lambda=538 \mathrm{~nm}$ and at $\lambda=505 \mathrm{~nm}$ was calculated for each sample. These two wavelengths correspond to $\mathrm{CR}$ absorption maximum observed when it is associated with $\beta$ structures, and to CR absorption peak when the dye is in its free state in solution. In order to compare this approach to the most commonly used protocol to quantify amyloid fibrils in solution, that is, Thioflavin $\mathrm{T}$ fluorescence measurements, the pattern of aggregation of the reference samples corresponding to lysozyme and insulin without cosolutes, was obtained by ThT measurements, too. The aggregation curves of the reference samples obtained by the two experimental methods were clearly overlapped (data reported in the Supplementary Materials).

For each result presented in this study, at least nine measurements were made, of which only the mean values are reported.

\subsection{Circular Dichroism}

$\mathrm{CD}$ measurements were performed at a room temperature of $20{ }^{\circ} \mathrm{C}$ with a Jasco J-715 spectropolarimeter, by using a circular quartz cell of $0.1 \mathrm{~mm}$ path-length. Protein concentration of samples was $c=0.1 \mathrm{mg} / \mathrm{mL}$, and it was obtained by diluting, with the proper buffer, the protein solutions thermically treated as described in Section 2.1. Reported CD spectra were obtained by taking the average of three scans made at $50 \mathrm{~nm} / \mathrm{min}$ from 260 to $190 \mathrm{~nm}$. Each spectrum was corrected for the baseline by subtracting the spectral contribution of the buffer solutions, and spectral data are expressed in units of millidegree.

\subsection{Small Angle X-ray Scattering}

SAXS data were collected at the ID02 beamline at the European Synchrotron Radiation Facility in Grenoble, France, and at the Austrian beamline of Elettra Synchrotron in Trieste, Italy [43]. Measurements were carried out at $20^{\circ} \mathrm{C}$ in capillaries of $1.5 \mathrm{~mm}$ outer diameter $/ 0.01 \mathrm{~mm}$ wall thickness made from borosilicate (Hilgenberg, Maisfeld, Germany) enclosed within a thermostatic compartment connected to an external circulation bath and a thermal probe for temperature control. Two dimensional patterns were recorded by Pilatus $1 \mathrm{M}$ detector system based on the CMOS hybrid pixel technology. The data were stored in TIF format and then directly processed with FIT2D [44]. We measured each sample 20 times with an acquisition time of $20 \mathrm{~s}$ and a rest time of $40 \mathrm{~s}$ for each step after a negative control for radiation damage and checked for consistency with literature values before usage [45]. According to this procedure we aim to reduce the possibility to induce radiation damage. Raw data were radially averaged, and calibrated in absolute units $\left(\mathrm{cm}^{-1}\right)$ by using a freshly prepared BSA solution $(5.0 \mathrm{mg} / \mathrm{mL})$ in phosphate buffer and water. The sample-to-detector distance was set to $1.247 \mathrm{~m}$, which provided wavenumbers $Q$ by the equation $Q=4 \pi \sin \theta / \lambda$, with $2 \theta$ being the scattering angle and $\lambda$ equal to $1.54 \AA$ the $X$-ray wavelength.

Both protein solutions (at concentration $c=3.0 \mathrm{mg} / \mathrm{mL}$ ) and buffers were measured at the same conditions concerning temperature and exposure time. The scattering curves have been normalized to the primary beam intensity, corrected for sample transmission and normalized to absolute scattering units. We carefully checked each set of scattering patterns and performed the average after a positive control over radiation damage. We did not observe radiation damage on samples presented in this study. 


\section{Results}

\subsection{LYSOZYME}

\subsubsection{Spectroscopy Results}

The influence of trehalose on lysozyme aggregation has been investigated analyzing the concomitant effectiveness of increasing ionic strength on the protein conformational evolution in time. The kinetics of the amyloid fibrillation for lysozyme in different selected conditions was at first monitored by UV/VIS absorption spectroscopy using CR as a probe for $\beta$-sheet formation. We underline that small aliquots of lysozyme in fibrillation conditions were kept from the stock solutions and then added with CR before UV/VIS analysis, thus we retain that the probe did not influence the fibrillation process. In Figure $1 \mathrm{few}$ exemplifying absorption spectra are reported. It can be noticed that, as expected, an absorption peak due to free $C R$ is present at $\simeq 500 \mathrm{~nm}$ at time 0 , that is, when no $\beta$ structures except the ones of the native folded protein, are present in solution. Instead, as the aggregation process proceeds, this unique initial peak converts to a wider signal due to the simultaneous presence in solution of free $C R$ and $C R$ bound to $\beta$ structures, these latter showing the typical absorption maximum at about $540 \mathrm{~nm}$ [34]. In the preparatory phase of the experiments, we successfully verified that the ratio between the area under the peak at higher wavelength and the area under the peak at lower wavelength, inside the error bars, was equal to the ratio between the corresponding intensities of the absorption peak due to CR bound to fibrils and the one due to $\mathrm{CR}$ free in solution. Thus, to estimate the relative amount of fibrils in solution, the ratio between the intensity of the absorption peak due to CR bound to fibrils and the intensity of the one due to $\mathrm{CR}$ free in solution was calculated. The obtained kinetic profiles describing lysozyme fibrillation are reported in Figure 2, where the relative amounts of $\beta$ sheet structures are plotted as a function of time, in different panels for various salt contents. These results derive from at least 9 replicas of each experiment. Regardless trehalose content, lysozyme shows an aggregation rate that increases with $\mathrm{NaCl}$ content, especially in the first $60 \mathrm{~min}$ when the nucleation phase occurs together with the formation of the oligomers and/or of the protofibrils. This evidence suggests that counterions added to the solution, shielding the charges located on protein surfaces, can favor the initial aggregation, thus confirming that electrostatic factors are crucial for amiloidogenesis [46]. In particular, at pH 2.3 lysozyme charge corresponds to $\simeq 18.8$ elementary charges, hence the electrostatic repulsion between proteins is very high, and the addition of counterions in solution determines an immediate screening of the charges and a consequent decrease of their repulsion, favoring a fast nucleation. It can be noticed that the elongation phase presents a certain regularity in terms of timing in all the examined cases, indeed, with the exception of the sample without $\mathrm{NaCl}$, the plateau occurs after about the first $90 \mathrm{~min}$. Concerning trehalose effect, as shown by the upper panel of Figure 2, amyloid fibril formation results almost blocked by the osmolyte, either for a concentration of 300 or $150 \mathrm{mM}$. On the other hand, upon addition of $\mathrm{NaCl} 25 \mathrm{mM}$, trehalose inhibitory action drastically weakens. As shown in the central panel of Figure 2, and said before, a fast nucleation takes place in these conditions, and the osmolyte action results just in a slight slowdown of the elongation phase and a little reduction of final amount of fibrillated structures. At higher ionic strength $(50 \mathrm{mM} \mathrm{NaCl}$, bottom panel of Figure 2), the presence of trehalose as a cosolute slows down only the very beginning of the aggregation process (the first $45 \mathrm{~min}$ ), and seems to be completely irrelevant for the final fibrillation. By observing the kinetics of fibrillation, it emerges that a strict direct proportionality between concentration of trehalose or $\mathrm{NaCl}$, and effect on kinetic profile is lacking. Data show how trehalose, in the absence of $\mathrm{NaCl}$, blocks the formation of amyloid fibers not strictly depending on its concentration, and its inhibiting action is greatly affected by the ionic strength regardless of salt concentration. On the other hand, the modest capability of the osmolyte to counteract the ionic strength effect is not always proportional to its concentration (see bottom panel in Figure 2). On the other side, in the presence of $\mathrm{NaCl}$ and regardless of its concentration, the inhibitory effect of trehalose appears to be affected. In fact, just a slight modification appears in the elongation phase, that is slown down at $25 \mathrm{mM} \mathrm{NaCl}$ with the higher 
amount of trehalose. We can resume that the amyloid aggregation of lysozyme is clearly influenced both by $\mathrm{NaCl}$ and by trehalose: protein fibrillation, observed by means of CR characteristic peak shift (Figure 2), is fastened by the presence of salt, even in low amount, and is blocked by the presence of trehalose, when the ionic strength is absent. Increasing the solution ionic strength, by adding $\mathrm{NaCl}$, the effect of trehalose is invalidated and the kinetic pattern is similar to the one in absence of cosolutes, with just some traceable changes in the rate of the process.

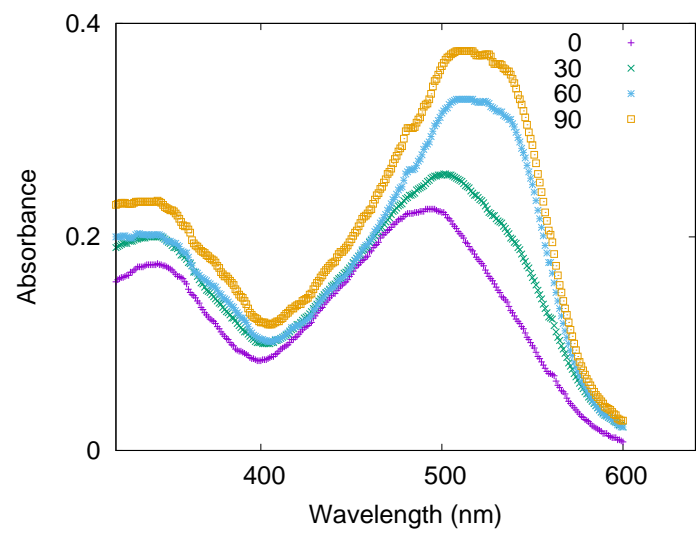

Figure 1. Absorption spectra of lysozyme at $c=3.0 \mathrm{mg} / \mathrm{mL}$, in the presence of CR and $50 \mathrm{mM} \mathrm{NaCl}$. Spectra were recorded as a function of time, expressed in minutes in the legend, during amyloid aggregation induced by a temperature of $65^{\circ} \mathrm{C}$.

Trehalose ability to interfere with lysozyme aggregation, as well as its combined effect with $\mathrm{NaCl}$, were validated by CD experiments, too. CD spectrum of native lysozyme (data not shown) is characterized by the presence of two minima at $208 \mathrm{~nm}$ and $222 \mathrm{~nm}$ [47], resulting by the combination of $\alpha$ and $\beta$ components, with a prevalence of $\alpha$-helical structure. The far-UV CD spectra measured on lysozyme solutions after different incubation times at $65^{\circ} \mathrm{C}$ are reported in Figure 3 . The two panels show CD spectra recorded in an intermediate phase (left panel) and in the final step (right panel) of lysozyme fibrillation, in the presence or the absence of trehalose and $\mathrm{NaCl}$. It can be appreciated that after $40 \mathrm{~min}$ (left panel), both the pure lysozyme solution and the one added with trehalose (150 $\mathrm{mM})$, present CD curves comparable to the one of the native protein, that is, lysozyme possesses in these conditions a secondary structure similar to the native one. On the contrary, in presence of trehalose plus $\mathrm{NaCl}(25 \mathrm{mM})$ a quite different band shape arises, indeed a negative CD band appears at around $215 \mathrm{~nm}$ as expected for $\beta$-sheet structures formation (see the top curve in the left panel of Figure 3) [39].

Thus, $\mathrm{CD}$ data confirm that, for lysozyme without trehalose and $\mathrm{NaCl}$, amyloidogenesis is still in its lag-phase after $40 \mathrm{~min}$ of incubation, and the same occurs in presence of trehalose. Instead, the simultaneous presence of trehalose and $\mathrm{NaCl}$ results in accelerating the amiloidogenesis in accordance with UV data commented above. By observing the right panel of Figure 3, it can be seen that CD spectrum recorded on lysozyme after $120 \mathrm{~min}$ of incubation (bottom trace) shows significant changes. Indeed, the two negative bands centered at 208 and $222 \mathrm{~nm}$, characteristic of the native state, convert into an intense negative single signal at $\simeq 215 \mathrm{~nm}$, indicating that the final fibrillation step is gained. A different trend is observed in presence of trehalose. In this case the CD curve (middle trace) retains a band shape comparable to the one of the native protein, thus confirming that the osmolyte can preserve lysozyme against self-aggregation. Addition of $\mathrm{NaCl}$ to the solution is able to nullify the trehalose effect, and a CD curve typically assigned to $\beta$-sheet structures is obtained again (see the top trace). Thus, CD data are in agreement with UV results previously described and collected on the basis of CR absorption, hence demonstrating that effects ascribed to trehalose or ionic strength are not related to the presence of the $C R$ probe. 

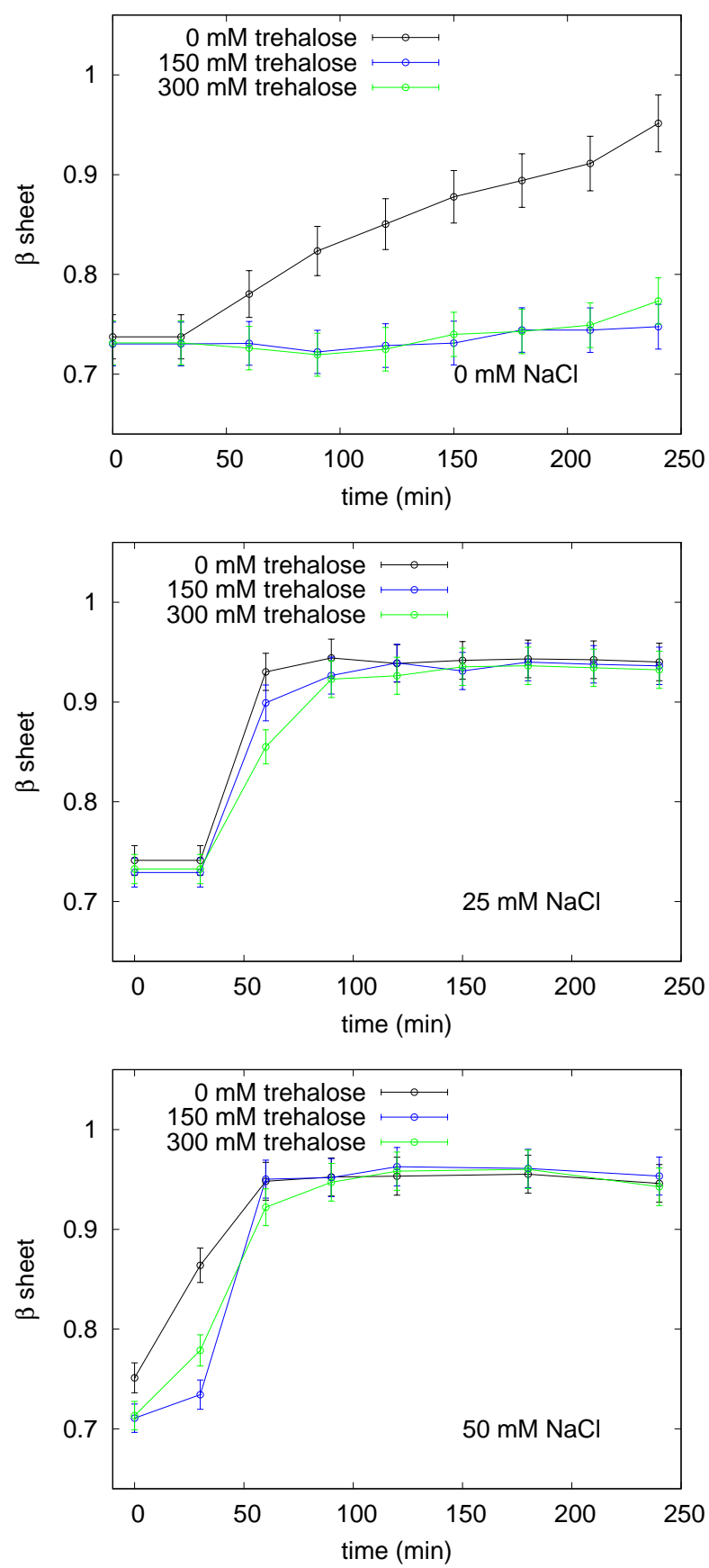

Figure 2. UV/VIS spectroscopy results on the effect of trehalose on lysozyme aggregation pattern. To monitor the relative amount of $\beta$-sheet structures in solution, the ratio between the intensity of the absorption peak due to Congo Red (CR) bound to fibrils and the one due to CR free in solution was calculated as a function of time. This ratio has been demonstrated to be proportional to $\beta$ structures in solution (see Section 2.2 and [48]). Black circles indicate the sample without trehalose, blue squares the sample with $150 \mathrm{mM}$ trehalose, and the green triangles the sample with $300 \mathrm{mM}$ trehalose. Top: samples without $\mathrm{NaCl}$, middle: with $25 \mathrm{mM} \mathrm{NaCl}$ and bottom: sample with $50 \mathrm{mM}$ $\mathrm{NaCl}$. The fibrillation kinetic of lysozyme in the absence of both trehalose and $\mathrm{NaCl}$, top panel, reaches its plateau after $240 \mathrm{~min}$, thus, for the sake of comparison, we report the first $240 \mathrm{~min}$ for all the investigated kinetics. The plateau values were confirmed, for each sample, after $24 \mathrm{~h}$ (data non reported). Error bars are estimated on the basis of the results of at least 9 replicas of the same experiment. 

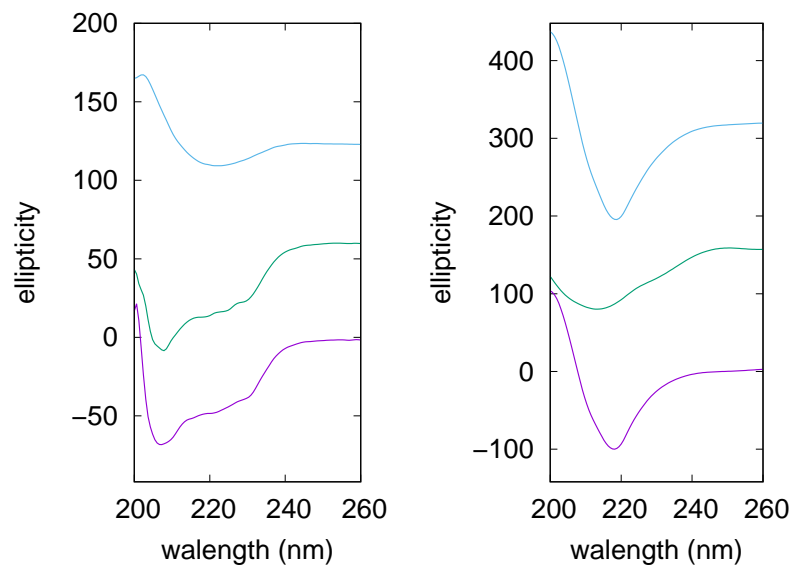

Figure 3. Circular Dichroism (CD) curves of lysozyme after $40 \mathrm{~min}$ (left) and after $120 \mathrm{~min}$ (right) at $65^{\circ} \mathrm{C}$. From bottom: lysozyme in solution without $\mathrm{NaCl}$ and without trehalose (violet), with $150 \mathrm{mM}$ trehalose (middle, green) and $0 \mathrm{mM} \mathrm{NaCl}$, with $150 \mathrm{mM}$ trehalose and $25 \mathrm{mM} \mathrm{NaCl}$ (top, cyan). All the curves are scaled for clarity and smoothed approximating the data with a natural smoothing spline.

\subsubsection{SAXS Results}

In order to monitor also the three-dimensional structures resulting from lysozyme aggregation into amyloid fibrils, we performed synchrotron SAXS measurements at the beginning and at the end of the aggregation processes. SAXS data concerning native hen-egg-white lysozyme at $\mathrm{pH} 2.3$ in glycine buffer with and without trehalose are reported in Figure 4. SAXS curve corresponding to lysozyme in presence of trehalose is comparable in shape to the one of the protein in the native state. In the inset SAXS data representation in the form of Kratky plot is presented to confirm the native conformation of the proteins. Kratky plots can qualitatively assess the flexibility and the degree of unfolding in samples: highly flexible proteins have a plateau in the Kratky plot at high $Q$ values, while compact, globular proteins will show a bell-shaped peak [49]. The bell-shape of these Kratky plots clearly states that the proteins are in native conformation. Furthermore both the curves can be successfully fitted by using the form factor calculated from 6LYZ PDB entry, by taking advantage of GENFIT software [50], and considering a higher density hydration shell according to SASMOL approach [51]. The unique difference between lysozyme in solution with trehalose and without it resides in the different contrast of the protein with the medium, which is due to trehalose contribution to the bulk electron density. Monitoring the final stages of lysozyme aggregation (samples analyzed $3 \mathrm{~h}$ after the beginning of the amyloid aggregation process), the presence of aggregates has been verified, as it is evident in the left panel of Figure 5. A simple Guinier analysis [49] for globular objects in solution, can provide model-free information on the gyration radius $R_{g}$ according to the approximation $\frac{d \Sigma}{d \Omega}(Q)=\frac{d \Sigma}{d \Omega}(0) e^{-Q^{2} R_{g}{ }^{2} / 3}$. For native lysozyme, the gyration radius obtained is around $16 \AA$, corresponding to lysozyme monomer dimension. The same sample after the three hour temperature treatment, cannot be fitted by the classical Guinier approximation, but it has been successfully fitted by using the Guinier rod-like approximation $\left(\frac{d \Sigma}{d \Omega}(Q)=\frac{1}{Q} \frac{d \Sigma}{d \Omega}(0) e^{-Q^{2} R_{c}{ }^{2} / 2}\right)$ that defines the cylindrical structure of the objects in solution (left panel of Figure 5). In particular, Guinier rod-like fitting accounted for the presence of at least two different families of elongated particles, the first one with a cross-sectional radius of about $77 \AA$, and the other one with a smaller radius of about $30 \AA$. This result confirms the amyloid aggregation of lysozyme, and the cross sectional radii are in agreement with those corresponding to mature amyloid fibrils (77 $⿱$ ) and to protofibrils ( $30 \AA$ ) and obtained by atomic force microscopy (AFM) [52]. Although spectroscopy results already proved the increase of $\beta$ structures as a consequence of lysozyme thermal treatment (see the black curve on the top panel of Figure 2), as well as ThT fluorescence spectroscopy experiments, SAXS results clearly demonstrate the three-dimensional features of the species in solution. SAXS data analysis proves the presence of at least two rod-like species that resemble fibrils and protofibrils and their simultaneous existence in solution resembles 
previous results on other amyloidogenic proteins $[53,54]$. Whilst Guinier rod-like approximation has the advantage to determine the average dimensions of elongated species without specific hypothesis, the whole SAXS curve is not fitted by this approximation.

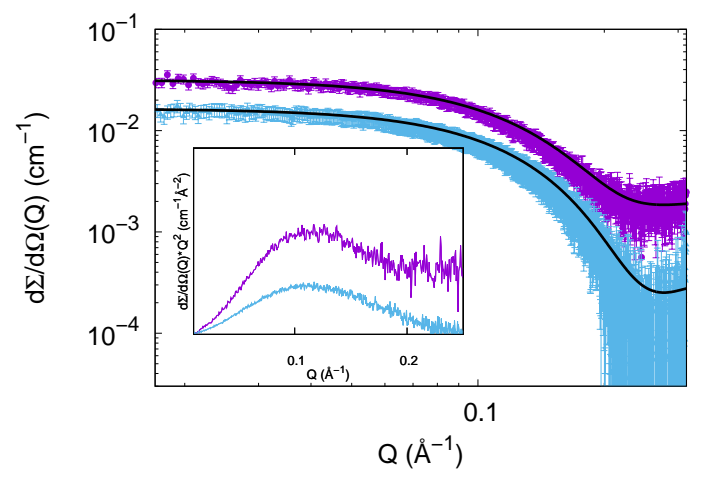

Figure 4. Small Angle X-ray Scattering (SAXS) curves of lysozyme at the beginning of the aggregation process at acidic $\mathrm{pH}$ : in absence (violet circles) and in presence (cyan triangles) of $150 \mathrm{mM}$ trehalose. Fitting curves refer to 6LYZ PDB entry. In the inset, Kratky plots of the curves are shown in order to confirm protein compactness.
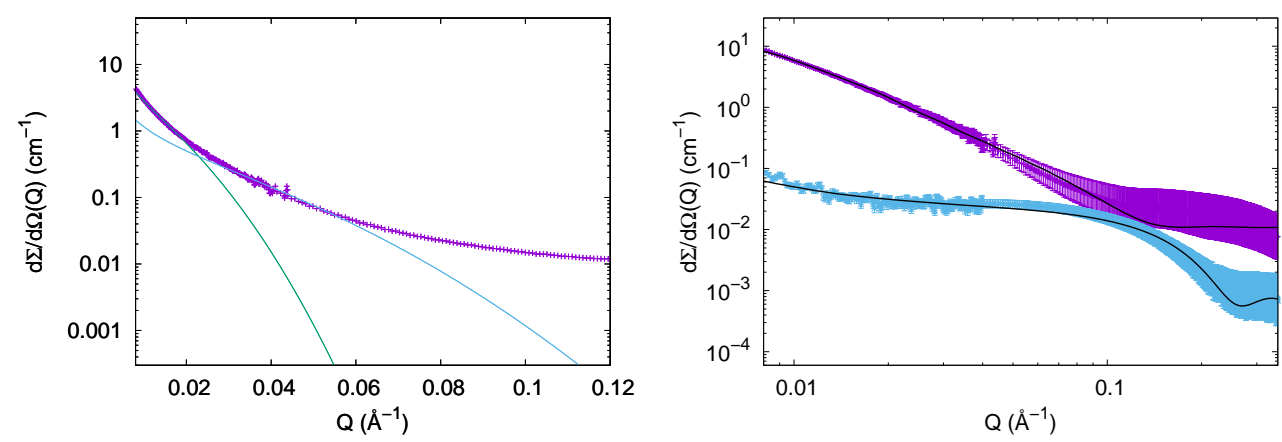

Figure 5. Experimental SAXS curves of lysozyme in different solutions at the end of the thermal treatment. Left panel reports SAXS experimental curve (violet points) and Guinier rod-like fitting of the final state of lysozyme aggregation, in absence of trehalose (cyan line corresponds to $R_{\mathcal{C}}=30 \AA$ and green line corresponds to $R_{c}=77 \AA$ ). Right panel reports SAXS experimental curves of lysozyme at the end of thermal treatment, in presence of trehalose (cyan points) and in absence of trehalose (violet points, curve shifted by a factor 2 for clarity). Continuous black lines represent the theoretical fitting obtained by considering disordered species in solution for lysozyme with trehalose, and by considering the simultaneous presence of cylinders and disordered species for lysozyme without trehalose.

Hence, we provided a further SAXS data analysis performed on all SAXS data points, and considering the simultaneous presence in solution of different species by GENFIT software [50]. This procedure has been already successfully applied to other cases of amyloidogenic proteins in solution [53], like $\alpha$-synuclein [55] and amyloid $\beta$-peptide [23]. Results are reported in the right panel of Figure 5, and the theoretical curves correctly fit SAXS spectra, confirming the presence of different species in solution and providing their structural features. In the final investigated time step of lysozyme in solution without trehalose, according to SAXS data analysis two species are present: one has a cylindrical shape (whose radius is polydispersed around $R=40 \AA$ ), confirming the fibrillar pattern, and the other is in a disordered conformation. In the final step of aggregation in presence of trehalose, instead the results are really different. In fact, the presence of trehalose inhibits the formation of fibrillar aggregates, allowing an analysis of SAXS data corresponding to the final state of the sample characterized uniquely by worm-like chains, fitted according to Pedersen Schurtenberger form factor model [56]. Two species of worm-like chains are present in solution: one with a low aggregation number (approximately 3), with a cross radius of $9.5 \pm 0.5 \AA$, and another with a high aggregation number (approximately 10), with a cross radius of $15.8 \pm 0.3 \AA$. It follows that trehalose prevents 
amyloid aggregation caused by the long thermal treatment. Due the large number of parameters needed to fit just one SAXS curve by two disordered species, parameters value do not provide a strong physical meaning, but merely confirm that trehalose prevents lysozyme fibrillation without preventing its unfolding due to both long term high temperature treatment and to very low $\mathrm{pH}$.

\subsection{INSULIN}

\subsubsection{Spectroscopy Results}

The kinetics of insulin denaturation and subsequent fibrillation are influenced by multiple parameters [38,40,57-59] and several cosolutes. In particular, it has been found that trehalose extends the lag phase of the fibrillation kinetic profile [58], thus slowing down amyloidogenesis. In the present work, we monitored insulin aggregation kinetic for further investigating trehalose effect also as a function of the ionic strength.

Analogously to the experimental procedure used for studying lysozyme, different protein samples were prepared with or without trehalose and/or $\mathrm{NaCl}$, and $\mathrm{UV}$ analysis was performed by using the $\mathrm{CR}$ dye as a probe for revealing $\beta$-sheet structures. The relative amounts of $\beta$ structure plotted versus time and obtained for the investigated samples are shown in Figure 6. The curve related to insulin solution incubated without salt and osmolyte exhibits the characteristic lag phase, elongation phase and maturation phase corresponding to the final plateau. It can be noticed that, upon addition of trehalose, the lag phase is enhanced, and its duration varies from $80 \mathrm{~min}$ to about $240 \mathrm{~min}$, as shown by the black traces reported in the two panels of Figure 6. In addition, a further effect concerns the final fibrillated structures, as the relative amount of detected $\beta$ structures reduces of about $10 \%$ in the presence of the osmolyte. As expected, addition of $\mathrm{NaCl}$ to the insulin solution causes a significant acceleration of fibrillation, indeed a drastic shortening of the elongation phase is evidenced. As seen for lysozyme, also in the case of insulin the presence of salt counteracts the aggregation inhibiting trehalose properties. In fact, for insulin solutions containing $\mathrm{NaCl}$ the kinetics of aggregation observed in the presence or in the absence of trehalose are very similar, as shown by the green traces in the two panels of Figure 6.
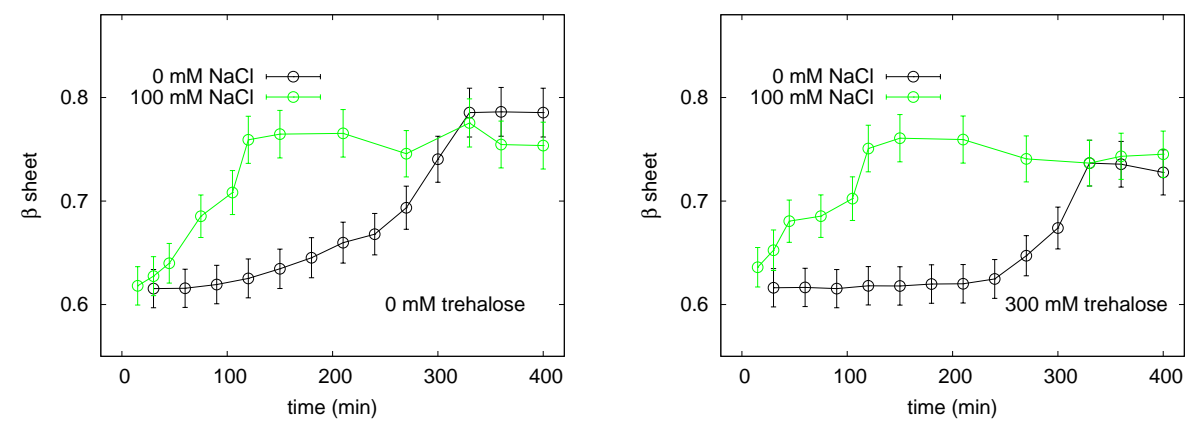

Figure 6. Analysis of the formation of $\beta$-sheet insulin structures in the absence and presence of trehalose (300 $\mathrm{mM})$. The vertical axis reports an estimation of the amount of $\beta$-sheet structures in solution, obtained by the ratio between the intensity of the absorption peak due to CR bound to fibrils and the one due to CR free in solution (details are reported in Section 2.2). Black points indicate samples without $\mathrm{NaCl}$, green circles represent the evolution of the sample with $100 \mathrm{mM} \mathrm{NaCl}$.

To confirm the similar conformational evolution of these two latter considered cases, solutions were monitored during fibrillation by CD measurements. CD curves obtained at different times are reported in Figure 7. It can be seen that analogous CD band shapes emerge for the two examined samples, that is, for insulin with $\mathrm{NaCl}$, in the presence (left panel) or in the absence (right panel) of trehalose. In both cases, after $30 \mathrm{~min}$ the native secondary structure is still detectable, while after 60 or $90 \mathrm{~min}$ the two characteristic minima are lost, and a single negative signal appears at $\simeq 220 \mathrm{~nm}$, in agreement with possible formation of $\beta$ sheet structures. 

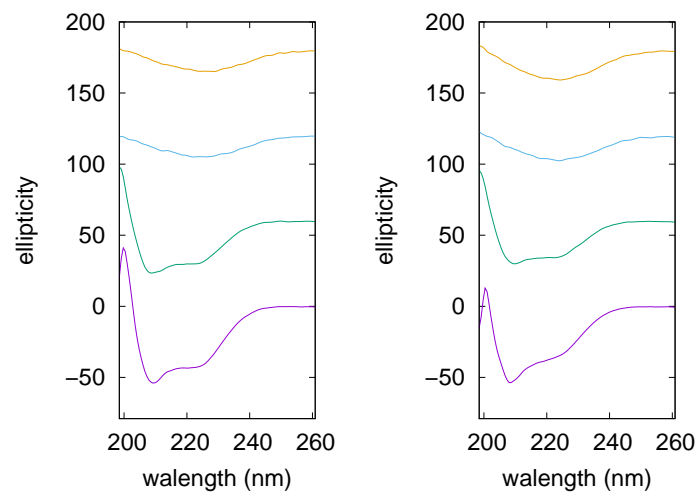

Figure 7. $\mathrm{CD}$ spectra recorded on insulin during incubation at $65^{\circ} \mathrm{C}$ in the presence of $\mathrm{NaCl} 100 \mathrm{mM}$, without trehalose (left panel) and with $300 \mathrm{mM}$ trehalose (right panel). The different curves correspond to different times: $0,30,60$, and $90 \mathrm{~min}$, from bottom to top.

$\mathrm{CD}$ data thus confirm that the presence of $\mathrm{NaCl}$ in solution erases the trehalose inhibiting effect on fibrillation.

\subsubsection{SAXS Results}

The efficacy of trehalose alone on the aggregation pattern of insulin has been validated instead by SAXS. The insulin solutions exposed to thermal treatments, in presence and absence of trehalose, have been observed after $4 \mathrm{~h}$ of incubation, to check the final states. Figure 8 clearly shows how SAXS fingerprints of those final stages are different from each other. SAXS data corresponding to insulin without trehalose present a trend at low $Q$ values that claims the presence of large aggregates. It should be noted that the same kinetics in presence of $\mathrm{NaCl}$ are not influenced by trehalose (data not showed). Hence a further SAXS data analysis was performed by GENFIT software [50] considering the simultaneous presence in solution of different species. Theoretical fittings together with experimental points are reported in Figure 8. SAXS data relative to insulin in solution without trehalose after the thermal treatment were fitted considering the predominant fibrillar state, populated by cylinders whose average radius measures $\simeq 38 \AA$, and is highly polydispersed (about $30 \%$ ), and a slight presence of disordered chains populated by less than $10 \%$ of the insulin monomers, whose cross section radius is about $20 \AA$. SAXS data corresponding to the sample subjected to the thermal treatment in presence of trehalose was successfully fitted by considering even in this case the same two different populations of objects in solution: polydispersed cylinders and disordered chains. However, we underline that in this case the predominant species is the disordered one $(\simeq 85 \%)$, while the cylindrical aggregates radii are wider in respect to the previous case (about $60 \AA$ ), probably suggesting a compaction among fibrils due to the presence of trehalose and consequent solvation changes.

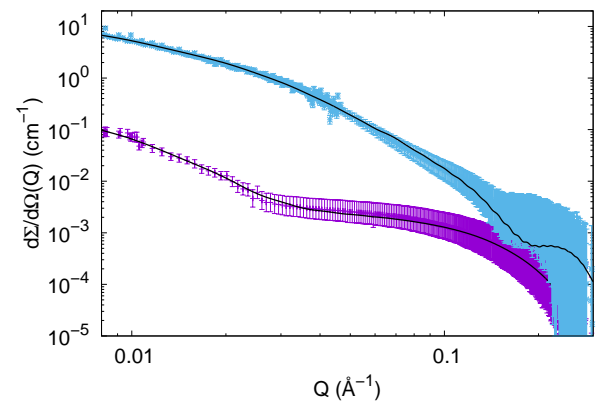

Figure 8. Experimental SAXS curves of insulin in different solutions at the end of the thermal treatment: in presence of trehalose (cyan points, curve shifted by a factor 4 for clarity) and in absence of trehalose (violet points). Continuous black lines represent the theoretical fitting obtained by considering disordered species and cylinders in solution, according to the details reported in Section 3.2. 


\section{Discussion and Conclusions}

The process of formation of amyloid fibers is a complex phenomenon that involves numerous factors such as the intrinsic properties of the proteins considered and the chemical and physical conditions of the environment (for example, $\mathrm{pH}$, temperature, ionic strength, concentration of the solution, agitation). In this study, the relationship between the fibrillation process of two model proteins, lysozyme and insulin, and the combined effects of trehalose and the ionic strength due to $\mathrm{NaCl}$ have been evaluated.

Trehalose, as an osmolyte, was known to increase protein stability and to move to higher values the melting temperature of proteins, thus favoring the native equilibrium of macromolecules [19]. Recent experimental data on the effect of trehalose on myoglobin thermal stability excluded the possibility that the protein can be stabilized by direct interaction with the trehalose molecules [60]. Instead, those results prompted that one to two molecular layers of water cover the protein surface and that the stabilizing trehalose molecules are generally located outside this hydration layer. According to this hypothesis, the trehalose-water matrix provides a stabilizing effect on the protein that increases with both the amount of trehalose-water around each protein (for a fixed water:trehalose ratio), as well as the concentration of trehalose in the surrounding solution [60]. The dynamics of the protein is thus, via the water layer, linked to the features of the trehalose-water matrix. These effects may allow the protein to be shielded from the environmental variations that induce denaturation, maintaining its own proper structure.

Our study confirms, for both the used proteins, trehalose effect against the fibrillation process, thus blocking, in the case of lysozyme, and inhibiting it, for insulin, as shown in Figures 2 and 6. The different effect of trehalose for lysozyme and insulin may be ascribed to the different intrinsic structure, size, charge, and stability of the two proteins. Lysozyme molecular weight is about triple than insulin one, and lysozyme charge is 18.8 elementary charges, while insulin charge is 4.9 elementary charges at the investigated experimental conditions. Lysozyme, showing in its native state a large and compact hydrophobic core, has four disulfide bridges that increase its stability [61], while the two short insulin polypeptide chains, more exposed to solvent, are linked by one intra-chain and two inter-chain disulfide bonds [62]. The amyloid aggregation is subsequent to the weakening of protein intrinsic architectures, concomitant with a misfolding and/or unfolding of their native structures [63]. As a consequence, the mode and the speed of proteins fibrillation cannot but be correlated with their misfolding. Hence, although trehalose effect has been considered to be totally non specific and mainly due to the preferential hydration mechanism [64], a different efficacy against lysozyme and insulin fibrillation is evidenced, possibly correlated with their different intrinsic stabilities. Both lysozyme and insulin amyloid fibrils maintain the disulfide bridges of their native structures $[62,65]$, hence disulfide bonds role is not easy to be inferred by our experiments.

The process of formation of amyloid fibers is influenced by the presence of $\mathrm{NaCl}$ in solution. Counterions screen protein surface charge, and as a consequence the coulombic repulsion between proteins decreases, favoring protein aggregation. The electrostatic contribution has been demonstrated to be an important factor in the amyloids formation [46], and an increase of salt concentration usually corresponds to a decrease of the lag time [33,34], as confirmed by our results (see Figures 2 and 6), although an inverted behaviour has been recently observed on D76N mutant Beta2-microglobulin case [66]. These different effects of the addition of counter-ions in solution can be related to their different nominal concentration in solution, and to the influence of protein charge in the fibrillation process, which can vary according to the solution $\mathrm{pH}$.

The main novelty of our study is in its focusing on the combined effect of trehalose and $\mathrm{NaCl}$ on protein fibrillation. In the case of insulin, the retarding effect of trehalose in fibrillation is completely canceled in the presence of $100 \mathrm{mM} \mathrm{NaCl}$. In the case of lysozyme, the inhibitory effect of the osmolyte in fibrillation is greatly modified by salt, trehalose impact reduces uniquely to a detectable slowing down of the nucleation phase, that does not prevent at all the amyloid fibers formation. In addition, in this work the concomitant effects on lysozyme and on insulin fibrillation due to trehalose and 
$\mathrm{NaCl}$ have been followed also by SAXS. SAXS data analysis provides the amount of species in solution and their structural features, and reveals that when both $\mathrm{NaCl}$ and trehalose are in solution with proteins during the thermal treatment, huge amount of disordered species forms in solution. Hence, the effect of the thermal treatment combined with $\mathrm{NaCl}$ presence in solution, makes trehalose ineffective in maintaining the protein intrinsic structure and determines an aspecific aggregation of disordered proteins.

These experimental results invoke caution in all those attempts looking for chemical agents able to interfere with amyloidogenesis of proteins, expecially of proteins related to neurodegenerative diseases. The physiological ionic strength averages around $150 \mathrm{mM}$, and according to our results the promising effect of trehalose $[19,20,59,67]$ fails in presence of $\mathrm{NaCl}$ even at concentrations lower than $100 \mathrm{mM}$. Other osmolytes have been found to positively interact against amyloidogenesis in vitro, as taurine, betaine, proline [39,68], but when in absence of a meaningful ionic strength in solution, those results should be considered with caution.

On the other hand, our results provide useful information to better understand the molecular mechanisms that trehalose adopts to act as a protective agent of biomolecules. The interaction of native proteins with the osmolyte endorse strengthening of hydrophobic interactions in the protein as a result of preferential exclusion of the osmolyte [35,39]. In absence of added salts, trehalose succeeds in maintaining the solvation sphere of the native protein thanks to the formation of a "water network", allowing proper hydration. The presence of ionic strength reverses this process. Indeed, upon addition of salt, the water molecules are engaged in solvating the ions, in our case, $\mathrm{Na}^{+}$and $\mathrm{Cl}^{-}$, located in particular in proximity of protein surface attracted by the electric charges. According to these considerations, the ions "steal" the water molecules that trehalose would like to organise onto the surface of the native protein, maintaining its hydration and, therefore, its correct folding.

The effect of $\mathrm{NaCl}$ on the system strengthens the "water entrapment" hypothesis for the osmolyte action, toward the "water replacement" one, that should not be affected by ions in solution.

Finally, trehalose, such as other carbohydrates, can accumulate in the cytoplasm of drought resistant cells, and is responsible for desiccation tolerance, as it is able to change the protein fibrillation pattern. Hence, exploitation of this osmolyte in several fields (food science, drug stability, bio-nanomaterials, etc.) could be very useful although a detailed description of its interaction with biomolecules is not yet completely established. The evaluation of trehalose ability to modify protein aggregation into amyloid fibrils in relation to the presence of $\mathrm{NaCl}$ is a new step toward the understanding of the interaction between the cosolute and the protein. Our study is an indirect confirm that the trapping of water molecules around the peptide can prevent structural damage [69] and consequent fibrillation, but noticeably underlines that this mechanism can be prevented by $\mathrm{NaCl}$ in solution. To conclude, we consider that in vitro experiments should take into account, step by step, nearly all the physiological factors that may possibly change their results when translated into an in vivo approach, and the ionic strength is a factor that cannot be neglected in protein fibrillation.

Supplementary Materials: The following are available at http:/ / www.mdpi.com/2075-1729/10/5/60/s1, Figure S1: UV/VIS spectroscopy results obtained with Congo Red (CR) and Fluorescence spectroscopy results obtained with Thioflavin T (ThT) on lysozyme aggregation pattern. Figure S2: UV/VIS spectroscopy results obtained with Congo Red (CR) and Fluorescence spectroscopy results obtained with Thioflavin T (ThT) on insulin aggregation pattern.

Author Contributions: C.R., E.M. and M.G.O. conceived and planned the experiments. E.M. and C.R. performed spectroscopy experiments. E.M., C.R. and S.P. performed CD experiments. F.S. and C.R. performed SAXS experiments. M.G.O., P.M., and S.P. provided biological materials, reagents, and all the tools necessary for the project. C.R., E.M. and M.G.O. analysed experimental data and wrote the paper. All authors discussed the results, commented and revised the manuscript. All authors have read and agreed to the published version of the manuscript.

Funding: This work was supported with a Scientific Research Grant by Marche Polytechnic University.

Acknowledgments: We thank the four anonymous reviewers whose comments and suggestions helped improve and clarify this manuscript. MGO thanks Giovanni Pietraroia and Maura Benedetti for experimental help in ThT fluorescence measurements reported in the Supplementary Materials, and Silvia Vilasi for stimulating discussions. 
Conflicts of Interest: The authors declare no conflict of interest.

\section{Abbreviations}

The following abbreviations are used in this manuscript:

MDPI Multidisciplinary Digital Publishing Institute

SAXS Small Angle X-ray Scattering

CD circular dichroism

\section{References}

1. Dyson, H.J.; Wright, P.E.; Scheraga, H.A. The role of hydrophobic interactions in initiation and propagation of protein folding. Proc. Natl. Acad. Sci. USA 2006, 103, 13057-13061. [CrossRef] [PubMed]

2. Walsh, G. Proteins Biochemistry and Biotechnology; Wiley: Hoboken, NJ, USA, 2014; pp. 1-23.

3. Foder, V.; Cataldo, S.; Librizzi, F.; Pignataro, B.; Spiccia, P.; Leone, M. Self-Organization Pathways and Spatial Heterogeneity in Insulin Amyloid Fibril Formation. J. Phys. Chem. B 2009, 113, 10830-10837, doi:10.1021/jp810972y. [CrossRef] [PubMed]

4. Manno, M.; Craparo, E.F.; Martorana, V.; Bulone, D.; Biagio, P.L.S. Kinetics of Insulin Aggregation: Disentanglement of Amyloid Fibrillation from Large-Size Cluster Formation. Biophys. J. 2006, 90, 4585-4591. [CrossRef]

5. Swaminathan, R.; Ravi, V.K.; Kumar, S.; Kumar, M.V.S.; Chandra, N. Lysozyme: A model protein for amyloid research. In Advances in Protein Chemistry and Structural Biology; Academic Press: Cambridge, MA, USA, 2011; Volume 84, pp. 63-111. [CrossRef]

6. Fernãndez, A.; de las Mercedes Boland, M. Solvent environment conducive to protein aggregation. FEBS Lett. 2002, 529, 298-302. [CrossRef]

7. Lee, E.; Choi, J.H.; Cho, M. The effect of Hofmeister anions on water structure at protein surfaces. Phys. Chem. Chem. Phys. 2017, 19, 20008-20015. [CrossRef] [PubMed]

8. Pedersen, J.S.; Flink, J.M.; Dikov, D.; Otzen, D.E. Sulfates dramatically stabilize a salt-dependent type of glucagon fibrils. Biophys. J. 2006, 90, 4181-4194. [CrossRef]

9. Munishkina, L.A.; Henriques, J.; Uversky, V.N.; Fink, A.L. Role of Protein-Water Interactions and Electrostatics in $\alpha$-Synuclein Fibril Formation. Biochemistry 2004, 43, 3289-3300. [CrossRef]

10. Okur, H.I.; Hladalkova, J.; Rembert, K.B.; Cho, Y.; Heyda, J.; Dzubiella, J.; Cremer, P.S.; Jungwirth, P. Beyond the Hofmeister Series: Ion-Specific Effects on Proteins and Their Biological Functions. J. Phys. Chem. B 2017, 121, 1997-2014, doi:10.1021/acs.jpcb.6b10797. [CrossRef] [PubMed]

11. Sinibaldi, R.; Ortore, M.G.; Spinozzi, F.; Carsughi, F.; Frielinghaus, H.; Cinelli, S.; Onori, G.; Mariani, P. Preferential hydration of lysozyme in water/glycerol mixtures: A small-angle neutron scattering study. J. Chem. Phys. 2007, 126. [CrossRef]

12. Spinozzi, F.; Ortore, M.G.; Sinibaldi, R.; Mariani, P.; Esposito, A.; Cinelli, S.; Onori, G. Microcalorimetric study of thermal unfolding of lysozyme in water/glycerol mixtures: An analysis by solvent exchange model. J. Chem. Phys. 2008, 129, 35101-35109. [CrossRef]

13. Gabel, F.; Ringkjøbing Jensen, M.; Zaccai, G.; Blackledge, M. Quantitative Modelfree Analysis of Urea Binding to Unfolded Ubiquitin Using a Combination of Small Angle X-ray and Neutron Scattering. J. Am. Chem. Soc. 2009, 131, 8769-8771. [CrossRef] [PubMed]

14. Ortore, M.G.; Sinibaldi, R.; Spinozzi, F.; Carsughi, F.; Clemens, D.; Bonincontro, A.; Mariani, P. New insights into urea action on proteins: SANS and Zeta Potential study of lysozyme. J. Phys. Chem. B 2008, 112, 12881-12887. [CrossRef] [PubMed]

15. Chron, N.; Naepels, M.; Pluharov, E.; Laage, D. Protein Preferential Solvation in Water: Glycerol Mixtures. J. Phys. Chem. B 2020, 124, 1424-1437, doi:10.1021/acs.jpcb.9b11190. [CrossRef] [PubMed]

16. Somero, G.N.; Yancey, P.H. Osmolytes and Cell-Volume Regulation: Physiological and Evolutionary Principles; American Cancer Society: Atlanta, GA, USA, 2011; pp. 441-484. [CrossRef]

17. Czech, L.; Hermann, L.; Stöveken, N.; Richter, A.A.; Höppner, A.; Smits, S.H.; Heider, J.; Bremer, E. Role of the extremolytes ectoine and hydroxyectoine as stress protectants and nutrients: Genetics, phylogenomics, biochemistry, and structural analysis. Genes 2018, 9, 177. [CrossRef] [PubMed] 
18. Meena, B.; Anbu Rajan, L.; Anandan, R. Protective effect of betaine on protein, glycoproteins and amino acids in isoprenaline-induced myocardial infarction in albino rats. Biomed. Prev. Nutr. 2014, 4, 403-409. [CrossRef]

19. Xie, G.; Timasheff, S.N. The thermodynamic mechanism of protein stabilization by trehalose. Biophys. Chem. 1997, 64, 25. [CrossRef]

20. Enzo, E. Can Trehalose Prevent Neurodegeneration? Insights from Experimental Studies. Curr. Drug Targets 2014, 15, 551-557. [CrossRef]

21. Zaman, M.; Khan, A.N.; Wahiduzzaman; Zakariya, S.M.; Khan, R.H. Protein misfolding, aggregation and mechanism of amyloid cytotoxicity: An overview and therapeutic strategies to inhibit aggregation. Int. J. Biol. Macromol. 2019, 134, 1022-1037. [CrossRef]

22. Aprile, F.A.; Sormanni, P.; Perni, M.; Arosio, P.; Linse, S.; Knowles, T.P.J.; Dobson, C.M.; Vendruscolo, M. Selective targeting of primary and secondary nucleation pathways in $\mathrm{A} \beta 42$ aggregation using a rational antibody scanning method. Sci. Adv. 2017, 3, e1700488. [CrossRef]

23. Battisti, A.; Palumbo Piccionello, A.; Sgarbossa, A.; Vilasi, S.; Ricci, C.; Ghetti, F.; Spinozzi, F.; Marino Gammazza, A.; Giacalone, V.; Martorana, A.; et al. Curcumin-like compounds designed to modify amyloid beta peptide aggregation patterns. RSC Adv. 2017, 7, 31714-31724. [CrossRef]

24. Ricci, C.; Spinozzi, F.; Mariani, P.; Ortore, M.; Grazia Ortore, M. Protein Amyloidogenesis Investigated by Small Angle Scattering. Curr. Pharm. Des. 2016, 22, 3937-3949. [CrossRef] [PubMed]

25. Galeazzi, R.; Laudadio, E.; Falconi, E.; Massaccesi, L.; Ercolani, L.; Mobbili, G.; Minnelli, C.; Sciré, A.; Cianfruglia, L.; Armeni, T. Proteinprotein interactions of human glyoxalase II: Findings of a reliable docking protocol. Org. Biomol. Chem. 2018, 16, 5167-5177. [CrossRef] [PubMed]

26. Elia, F.; Cantini, F.; Chiti, F.; Dobson, C.M.; Bemporad, F. Direct Conversion of an Enzyme from Native-like to Amyloid-like Aggregates within Inclusion Bodies. Biophys. J. 2017, 112, 2540-2551. [CrossRef] [PubMed]

27. Kushwah, N.; Jain, V.; Yadav, D. Osmolytes: A Possible Therapeutic Molecule for Ameliorating the Neurodegeneration Caused by Protein Misfolding and Aggregation. Biomolecules 2020, 10, 132. [CrossRef]

28. Uversky, V.N.; Finkelstein, A.V. Life in Phases: Intra- and Inter- Molecular Phase Transitions in Protein Solutions. Biomolecules 2019, 9, 842. [CrossRef]

29. Kuehner, D.E.; Engmann, J.; Fergg, F.; Wernick, M.; Blanch, H.W.; Prausnitz, J.M. Lysozyme Net Charge and Ion Binding in Concentrated Aqueous Electrolyte Solutions. J. Phys. Chem. B 1999, 103, 1368-1374. [CrossRef]

30. Zhang, Y.; Cremer, P.S. Interactions between macromolecules and ions: The Hofmeister series. Curr. Opin. Chem. Biol. 2006, 10, 658-663. [CrossRef]

31. Jain, S.; Udgaonkar, J.B. Salt-induced modulation of the pathway of amyloid fibril formation by the mouse prion protein. Biochemistry 2010, 49, 7615-7624. [CrossRef]

32. Bye, J.W.; Falconer, R.J. Thermal stability of lysozyme as a function of ion concentration: A reappraisal of the relationship between the Hofmeister series and protein stability. Protein Sci. 2013, 22, 1563-1570. [CrossRef]

33. Poniková, S.; Antošová, A.; Demjén, E.; Sedláková, D.; Marek, J.; Varhač, R.; Gažová, Z.; Sedlák, E. Lysozyme stability and amyloid fibrillization dependence on Hofmeister anions in acidic pH. J. Biol. Inorg. Chem. 2015, 20, 921-933. [CrossRef]

34. Muzaffar, M.; Ahmad, A. The mechanism of enhanced insulin amyloid fibril formation by $\mathrm{NaCl}$ is better explained by a conformational change model. PLoS ONE 2011, 6, e27906. [CrossRef]

35. Soper, A.K.; Ricci, M.A.; Bruni, F.; Rhys, N.H.; McLain, S.E. Trehalose in Water Revisited. J. Phys. Chem. B 2018, 122, 7365-7374. [CrossRef] [PubMed]

36. Sakhaee, N.; Sakhaee, S.; Takallou, A.; Mobaraki, A.; Maddah, M.; Moshrefi, R. Hydrodynamic volume of trehalose and its water uptake mechanism. Biophys. Chem. 2019, 249. [CrossRef]

37. Ajito, S.; Hirai, M.; Iwase, H.; Shimizu, N.; Igarashi, N.; Ohta, N. Protective action of trehalose and glucose on protein hydration shell clarified by using X-ray and neutron scattering. Phys. B Condens. Matter 2018, 551, 249-255. [CrossRef]

38. Chatani, E.; Imamura, H.; Yamamoto, N.; Kato, M. Stepwise Organization of the -Structure Identifies Key Regions Essential for the Propagation and Cytotoxicity of Insulin Amyloid Fibrils. J. Biol. Chem. 2014, 289, 10399-10410. [CrossRef] [PubMed]

39. Choudhary, S.; Kishore, N.; Hosur, R.V. Inhibition of insulin fibrillation by osmolytes: Mechanistic Insights. Sci. Rep. 2015, 5. [CrossRef] [PubMed] 
40. Chatani, E.; Inoue, R.; Imamura, H.; Sugiyama, M.; Kato, M.; Yamamoto, M.; Nishida, K.; Kanaya, T. Early aggregation preceding the nucleation of insulin amyloid fibrils as monitored by small angle X-ray scattering. Sci. Rep. 2015, 5, 15485. [CrossRef]

41. Frid, P.; Anisimov, S.V.; Popovic, N. Congo red and protein aggregation in neurodegenerative diseases. Brain Res. Rev. 2007, 53, 135-160. [CrossRef]

42. Khurana, R.; Uversky, V.N.; Nielsen, L.; Fink, A.L. Is Congo Red an Amyloid-specific Dye? J. Biol. Chem. 2001, 276, 22715-22721. [CrossRef]

43. Amenitsch, H.; Rappolt, M.; Kriechbaum, M.; Mio, H.; Laggner, P.; Bernstorff, S. First performance assessment of the small-angle X-ray scattering beamline at ELETTRA. J. Synchrotron Radiat. 1998, 5, 506-508. [CrossRef] [PubMed]

44. Hammersley, A.P.; Brown, K.; Burmeister, W.; Claustre, L.; Gonzalez, A.; McSweeney, S.; Mitchell, E.; Moy, J.P.; Svensson, S.O.; Thompson, A.W. Calibration and application of an X-ray image intensifier/charge-coupled device detector for monochromatic macromolecular crystallography. J. Synchrotron Radiat. 1997, 4, 67-77. [CrossRef] [PubMed]

45. Mylonas, E.; Svergun, D. Accuracy of molecular mass determination of proteins in solution by small-angle X-ray scattering. J. Appl. Cryst. 2007, 40, s245-s249. [CrossRef]

46. Foderà, V.; Zaccone, A.; Lattuada, M.; Donald, A.M. Electrostatics Controls the Formation of Amyloid Superstructures in Protein Aggregation. Phys. Rev. Lett. 2013, 111, 108105. [CrossRef] [PubMed]

47. Gu, Z.; Zhu, X.; Ni, S.; Su, Z.; Zhou, H.M. Conformational changes of lysozyme refolding intermediates and implications for aggregation and renaturation. Int. J. Biochem. Cell Biol. 2004, 36, 795-805. [CrossRef] [PubMed]

48. Wu, J.W.; Liu, K.N.; How, S.C.; Chen, W.A.; Lai, C.M.; Liu, H.S.; Hu, C.J.; Wang, S.S.S. Carnosine's Effect on Amyloid Fibril Formation and Induced Cytotoxicity of Lysozyme. PLoS ONE 2013, 8, e81982. [CrossRef]

49. Glatter, O. Fourier Transformation and Deconvolution; North-Holland: Amsterdam, The Netherlands, 2002; pp. 103-124.

50. Spinozzi, F.; Ferrero, C.; Ortore, M.G.; De Maria Antolinos, A.; Mariani, P. GENFIT: Software for the analysis of small-angle X-ray and neutron scattering data of macro-molecules in solution. J. Appl. Crystallogr. 2014, 47, 1132-1139. [CrossRef]

51. Ortore, M.G.; Spinozzi, F.; Mariani, P.; Paciaroni, A.; Barbosa, L.R.S.; Amenitsch, H.; Steinhart, M.; Ollivier, J.; Russo, D. Combining structure and dynamics: Non-denaturing high-pressure effect on lysozyme in solution. J. R. Soc. Interface 2009, 6 (Suppl. 5), S619-S634. [CrossRef]

52. Hill, S.E.; Robinson, J.; Matthews, G.; Muschol, M. Amyloid Protofibrils of Lysozyme Nucleate and Grow Via Oligomer Fusion. Biophys. J. 2009, 96, 3781-3790. [CrossRef]

53. Ortore, M.G.; Spinozzi, F.; Vilasi, S.; Sirangelo, I.; Irace, G.; Shukla, A.; Narayanan, T.; Sinibaldi, R.; Mariani, P. Time-resolved small-angle $X$-ray scattering study of the early stage of amyloid formation of an apomyoglobin mutant. Phys. Rev. E 2011, 84, 061904. [CrossRef]

54. Mangione, M.R.; Palumbo Piccionello, A.; Marino, C.; Ortore, M.G.; Picone, P.; Vilasi, S.; Di Carlo, M.; Buscemi, S.; Bulone, D.; San Biagio, P.L. Photo-inhibition of A[small beta] fibrillation mediated by a newly designed fluorinated oxadiazole. RSC Adv. 2015, 5, 16540-16548. [CrossRef]

55. Piccirilli, F.; Plotegher, N.; Spinozzi, F.; Bubacco, L.; Mariani, P.; Beltramini, M.; Tessari, I.; Militello, V.; Perucchi, A.; Amenitsch, H.; et al. Pressure effects on $\alpha$-synuclein amyloid fibrils: An experimental investigation on their dissociation and reversible nature. Arch. Biochem. Biophys. 2017, 627, 46-55. [CrossRef]

56. Pedersen, J.S.; Schurtenberger, P. Scattering Functions of Semiflexible Polymers with and without Excluded Volume Effects. Macromolecules 1996, 29, 7602-7612. [CrossRef]

57. Bekard, I.B.; Dunstan, D.E. Tyrosine Autofluorescence as a Measure of Bovine Insulin Fibrillation. Biophys. J. 2009, 97, 2521-2531. [CrossRef] [PubMed]

58. Vilasi, S.; Iannuzzi, C.; Portaccio, M.; Irace, G.; Sirangelo, I. Effect of Trehalose on W7FW14F Apomyoglobin and Insulin Fibrillization: New Insight into Inhibition Activity. Biochemistry 2008, 47, 1789-1796. [CrossRef]

59. Arora, A.; Ha, C.; Park, C.B. Inhibition of insulin amyloid formation by small stress molecules. FEBS Lett. 2004, 564, 121-125. [CrossRef]

60. Olsson, C.; Jansson, H.; Swenson, J. The role of trehalose for the stabilization of proteins. J. Phys. Chem. B 2016, 120, 4723-4731. [CrossRef] 
61. Guez, V.; Roux, P.; Navon, A.; Goldberg, M.E. Role of individual disulfide bonds in hen lysozyme early folding steps. Protein Sci. 2002, 11, 1136-1151. [CrossRef]

62. Kurouski, D.; Washington, J.; Ozbil, M.; Prabhakar, R.; Shekhtman, A.; Lednev, I.K. Disulfide Bridges Remain Intact while Native Insulin Converts into Amyloid Fibrils. PLoS ONE 2012, 7, e36989. [CrossRef] [PubMed]

63. Knowles, T.P.J.; Vendruscolo, M.; Dobson, C.M. The amyloid state and its association with protein misfolding diseases. Nat. Rev. Mol. Cell Biol. 2014, 15, 384-396. [CrossRef]

64. Cordone, L.; Cottone, G.; Cupane, A.; Emanuele, A.; Giuffrida, S.; Levantino, M. Proteins in Saccharides Matrices and the Trehalose Peculiarity: Biochemical and Biophysical Properties. Curr. Org. Chem. 2015, 19, 1684-1706. [CrossRef]

65. Booth, D.R.; Sunde, M.; Bellotti, V.; Robinson, C.V.; Hutchinson, W.L.; Fraser, P.E.; Hawkins, P.N.; Dobson, C.M.; Radford, S.E.; Blake, C.C.F.; et al. Instability, unfolding and aggregation of human lysozyme variants underlying amyloid fibrillogenesis. Nature 1997, 385, 787-793. [CrossRef] [PubMed]

66. Visconti, L.; Malagrin, F.; Broggini, L.; De Luca, C.M.G.; Moda, F.; Gianni, S.; Ricagno, S.; Toto, A. Investigating the Molecular Basis of the Aggregation Propensity of the Pathological D76N Mutant of Beta-2 Microglobulin: Role of the Denatured State. Int. J. Mol. Sci. 2019, 20, 396. [CrossRef] [PubMed]

67. Liu, R.; Barkhordarian, H.; Emadi, S.; Chan, B.P.; Sierks, M.R. Trehalose differentially inhibits aggregation and neurotoxicity of beta-amyloid 40 and 42. Neurobiol. Dis. 2005, 20, 74-81. [CrossRef]

68. Santa-María, I.; Hernández, F.; Moreno, F.J.; Avila, J. Taurine, an inducer for tau polymerization and a weak inhibitor for amyloid- $\beta$-peptide aggregation. Neurosci. Lett. 2007, 429, 91-94. [CrossRef] [PubMed]

69. Di Gioacchino, M.; Bruni, F.; Ricci, M.A. Protection against Dehydration: A Neutron Diffraction Study on Aqueous Solutions of a Model Peptide and Trehalose. J. Phys. Chem. B 2018, 122, 10291-10295, doi:10.1021/acs.jpcb.8b08046. [CrossRef] [PubMed]

(C) 2020 by the authors. Licensee MDPI, Basel, Switzerland. This article is an open access article distributed under the terms and conditions of the Creative Commons Attribution (CC BY) license (http:/ / creativecommons.org/licenses/by/4.0/). 